\title{
Practices and Perspectives in Cardiopulmonary Resuscitation Attempts and the Use of Do Not Attempt Resuscitation Orders: A Cross-sectional Survey in Sri Lanka
}

\author{
Abi Beane ${ }^{1,2,3}$, Ambepitiyawaduge Pubudu De Silva ${ }^{1,4,5}$, Kaushila Thilakasiri' ${ }^{1}$, Tim Stephens ${ }^{1,6,7}$, Anuruddha Padeniya ${ }^{8,9,10}$, Priyantha Athapattu ${ }^{4,11}$, \\ Palitha G. Mahipala' ${ }^{12}$, Ponsuge Chathurani Sigera ${ }^{1,4}$, Arjen M. Dondorp², Rashan Haniffa ${ }^{1,2,4,13}$
}

${ }^{1}$ Network for Improving Critical Care Systems and Training, Colombo, Sri Lanka, ${ }^{2}$ Mahidol Oxford Tropical Medicine Research Unit (MORU), Bangkok, Thailand, ${ }^{3}$ Academic Medical Centre, Amsterdam, Netherlands, ${ }^{4}$ National Intensive Care Surveillance, Ministry of Health, Colombo, Sri Lanka, ${ }^{5}$ ntensive Care National Audit and Research Centre, ${ }^{6}$ Critical Care Research Team, Royal London Hospital, ${ }^{7}$ William Harvey Institute, Queen Mary University of London, London, United Kingdom, ${ }^{8}$ Lady Ridgeway Hospital, Colombo, ${ }^{9}$ Faculty of Medicine, University of Rajarata, Anuradhapura, ${ }^{10}$ Government Medical Officers Association, ${ }^{11}$ Office of Director Medical Services, Ministry of Health, ${ }^{12}$ Office of Director General of Health Services, Ministry of Health, ${ }^{13}$ Faculty of Medicine, University of Colombo, Colombo, Sri Lanka

\section{Abstract}

Objective: The objective of this study is to describe the characteristics of in-hospital cardiopulmonary resuscitation (CPR) attempts, the perspectives of junior doctors involved in those attempts and the use of do not attempt resuscitation (DNAR) orders. Methods: A cross-sectional telephone survey aimed at intern doctors working in all medical/surgical wards in government hospitals. Interns were interviewed based on the above objective. Results: A total of 42 CPR attempts from 82 hospitals ( 338 wards) were reported, 3 of which were excluded as the participating doctor was unavailable for interview. 16 (4.7\%) wards had at least 1 patient with an informal DNAR order. 42 deaths were reported. 8 deaths occurred without a known resuscitation attempt, of which 6 occurred on wards with an informal DNAR order in place. 39 resuscitations were attempted. Survival at $24 \mathrm{~h}$ was 2 (5.1\%). In 5 (13\%) attempts, CPR was the only intervention reported. On 25 (64\%) occasions, doctors were "not at all" or "only a little bit surprised" by the arrest. Conclusions: CPR attempts before death in hospitals across Sri Lanka is prevalent. DNAR use remains uncommon.

Keywords: Cardiopulmonary resuscitation, critical care, do not attempt cardiopulmonary resuscitation, resource-limited, resuscitation

\section{INTRODUCTION}

Resuscitation following cardiac arrests occurring either as an end of life event or after maximal treatment are unlikely to be successful and may result in loss of patient dignity and futility. ${ }^{[1-3]}$ In such situations, proactive do not attempt cardiopulmonary resuscitation (DNACPR) orders are increasingly being used in high-income countries (HICs). ${ }^{[4,5]}$ National data from Sri Lanka, a low-middle income country (LMIC), indicates that the majority $(87 \%)$ hospital deaths are preceded by resuscitation. ${ }^{[6]}$

This suggests that some patients, for whom the likelihood of survival is minimal, are receiving futile and unnecessary resuscitation attempts. Recent data from Intensive Care Units (ICUs) in LMICs suggests formal DNACPR orders remain uncommon. ${ }^{[3]}$

\begin{tabular}{|c|c|}
\hline \multicolumn{2}{|c|}{ Access this article online } \\
\hline Quick Response Code: & $\begin{array}{l}\text { Website: } \\
\text { www.ijccm.org }\end{array}$ \\
\hline H & $\begin{array}{l}\text { DOI: } \\
10.4103 / \text { ijccm.IJCCM_314_17 }\end{array}$ \\
\hline
\end{tabular}

This paper reports on the results of a survey, in adults in acute hospital ward settings across Sri Lanka, to establish the characteristics of resuscitation attempts, immediate outcomes after cardiac arrest, and DNACPR usage.

\section{Materials and Methods}

A cross-sectional survey was conducted in all adult general wards in Sri Lanka hospitals where medical or surgical patients are treated under the care of specialist (consultant)

Address for correspondence: Dr. Rashan Haniffa National Intensive Care Surveillance, Quality Secretariat Building, Castle Street Hospital for Women, Colombo 08, Sri Lanka. E-mail: rashan@nicslk.com

This is an open access article distributed under the terms of the Creative Commons Attribution-NonCommercial-ShareAlike 3.0 License, which allows others to remix, tweak, and build upon the work non-commercially, as long as the author is credited and the new creations are licensed under the identical terms.

For reprints contact: reprints@medknow.com

How to cite this article: Beane A, Ambepitiyawaduge PD, Thilakasiri K, Stephens T, Padeniya A, Athapattu P, et al. Practices and perspectives in cardiopulmonary resuscitation attempts and the use of do not attempt resuscitation orders: A cross-sectional survey in Sri Lanka. Indian J Crit Care Med 2017;21:865-8. 
doctors $(n=90)$. Specialty-specific wards such as Obstetrics and Gynaecology were not included in this study.

Wards were contacted by telephone. In each ward, a house officer (HO, a junior doctor undergoing internship training) was invited to participate in an anonymous, short, structured interview describing resuscitation attempts for which they were present, during their previous shift of $36 \mathrm{~h}$. These doctors typically cover shifts consisting of a day, followed by a night on call, followed immediately by a day shift. HOs in Sri Lanka are allocated to one ward for several months and invariably participate or lead in-ward resuscitation following cardiac arrest.

Calls were made by the investigators and were repeated if the HO's were unavailable on initial contact. Responses were electronically collated.

The survey tool consisted of questions to determine the number of deaths in the ward, attempted resuscitations and their outcomes, postresuscitation status, and prevalence of DNACPR orders. For each resuscitation attempt where the HO participated, the survey explored the objective practices of; defibrillation, intubation, use of adrenaline, postresuscitation care and whether a senior doctor was contacted during the resuscitation attempt. Further questions ascertained the extent of surprise felt by the doctor regarding the event and the perceived probability of success following attempted resuscitation.

Descriptive analysis was undertaken based on the characteristics of resuscitation attempts associated with the chain of survival. The study was conducted in collaboration with the Government Medical Officers Association, Ministry of Health and Network for Improving Critical care Systems and Training (NICST). The study was funded by the NICST. ${ }^{[6]}$

\section{RESULTS}

During the survey, 82 of the 90 target hospitals were successfully contacted. A total of 336 adult general wards in these 82 hospitals were contacted. HO's in two wards declined to participate. Study findings are summarized in Figure 1 and Table 1.

A total of 39 resuscitation attempts were surveyed. A further three attempts had no further information available as the $\mathrm{HO}$ interviewed was aware of, but did not participate in the resuscitation attempt. Of these 39 attempts, 34 (87.2\%) were immediately unsuccessful. Five $(12.8 \%)$ attempts resulted in Return of Spontaneous Circulation (ROSC) with three patients being transferred to ICU for postresuscitation care while the other two patients remained on the ward. HO were able to report that $24 \mathrm{~h}$ from the time of resuscitation, only the two patients transferred to an ICU were still alive (5.1\%), with outcome for the third patient in the ICU was unknown. Eight deaths occurred without a known resuscitation attempt. Of these 6 deaths occurred on wards where there were informal DNACPR instructions in place though it is not known whether these particular patients had treatment limitations. In total,

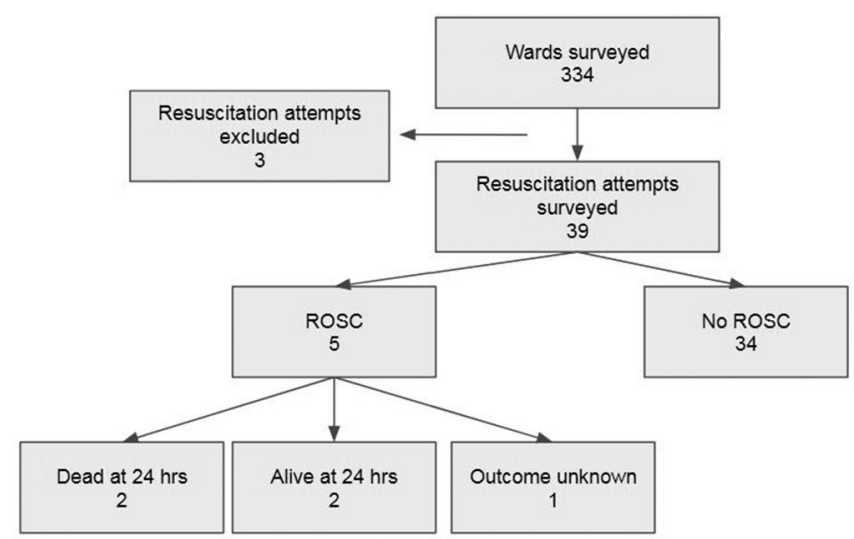

Figure 1: Outcomes of resuscitation attempts surveyed

\begin{tabular}{|c|c|}
\hline Characteristics of resuscitation attempts $(n=39)$ & $n(\%)$ \\
\hline \multicolumn{2}{|l|}{ Alerted by } \\
\hline Staff member & $26(66.7)$ \\
\hline Visitor/family member & $11(28.2)$ \\
\hline Other & $2(5.1)$ \\
\hline \multicolumn{2}{|l|}{ Family member(s) present during CPR } \\
\hline Present & $29(74.3)$ \\
\hline Not present & $10(25.6)$ \\
\hline \multicolumn{2}{|l|}{ Defibrillation } \\
\hline Attempted & $5(12.8)$ \\
\hline Not attempted & $34(87.2)$ \\
\hline \multicolumn{2}{|l|}{ Intubation } \\
\hline Attempted & $3(7.7)$ \\
\hline Not attempted & $36(92.3)$ \\
\hline \multicolumn{2}{|l|}{ Adrenaline } \\
\hline None & $5(12.8)$ \\
\hline 1 vial & $9(23.1)$ \\
\hline$>1$ vial & $25(64.1)$ \\
\hline \multicolumn{2}{|l|}{ Other drugs given during $\mathrm{CPR}$} \\
\hline Atropine & $11(28.2)$ \\
\hline Inotrope & $4(10.2)$ \\
\hline Other & $3(7.7)$ \\
\hline \multicolumn{2}{|l|}{ More senior doctor informed } \\
\hline No & $9(23.0)$ \\
\hline Yes & $30(77.0)$ \\
\hline $\mathrm{SHO} /$ registrar & $20(51.3)$ \\
\hline Consultant & $10(25.7)$ \\
\hline
\end{tabular}

CPR: Cardiopulmonary resuscitation; SHO: Senior house officer

15 wards (4.4\%) in 12 different hospitals had at least one patient with informal DNACPR instructions. Thirteen of these $(86.6 \%)$ were medical wards.

Of the five resuscitation attempts that resulted in ROSC, doctors reported that they were "somewhat surprised" or "very surprised" on all 5 (100\%) of occasions. Conversely, $82 \%$ of respondents indicated little or no surprise in those patients who had unsuccessful resuscitation attempts. They further reported that they felt the likelihood of a successful outcome was an "even chance" to "very likely" in all these ROSC instances. 


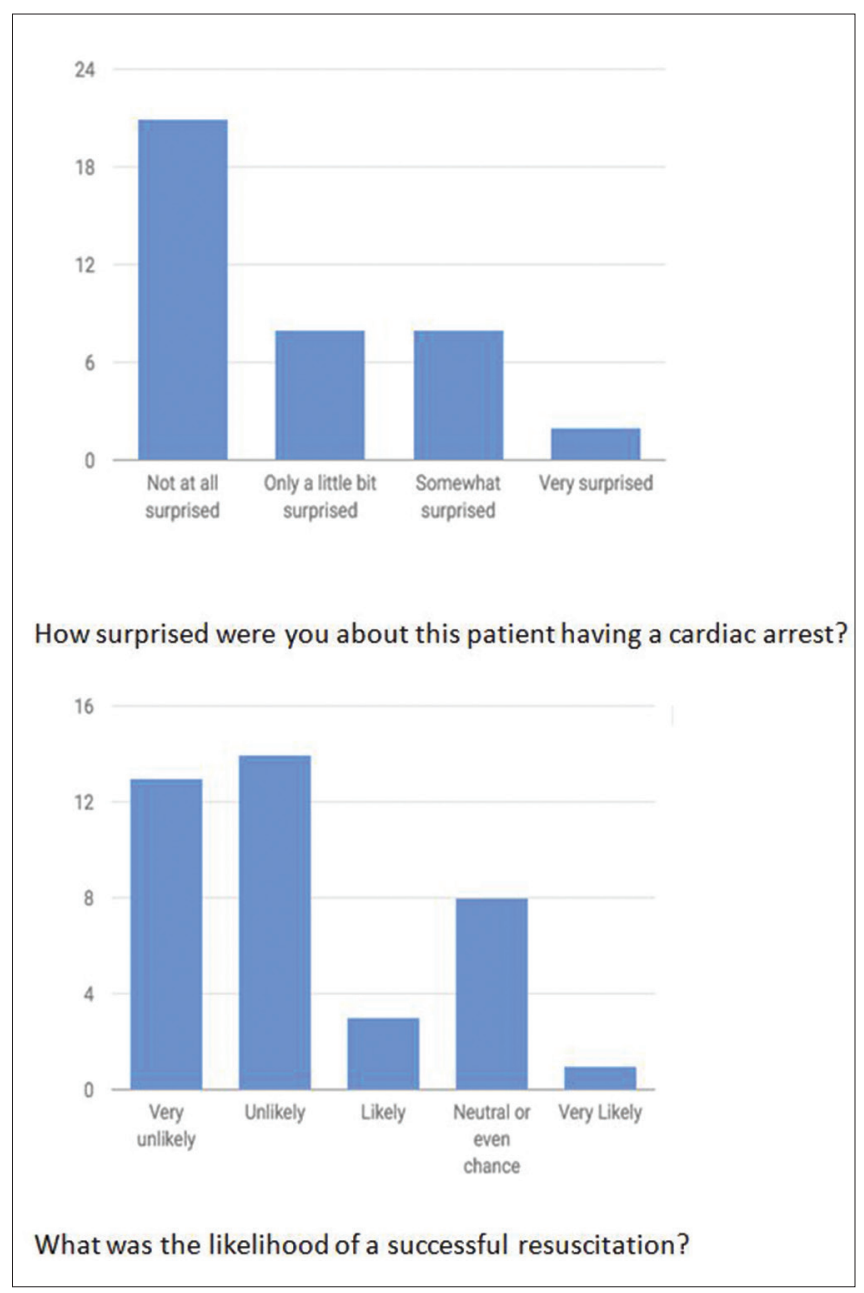

Figure 2: House officer perspectives regarding cardiac arrest occurrence and outcome

\section{Discussion}

This national survey of resuscitation in Sri Lanka confirms that the majority $(80.9 \%)$ of in-patient deaths in general wards are preceded by some attempts at cardiopulmonary resuscitation (CPR). In contrast, in Singapore, this number may be as low as $33.8 \%$, for patients outside the ICU. ${ }^{[3]}$ The majority $(87.2 \%)$ of patients were not defibrillated, suggesting nonshockable rhythms as the cause of arrest, though a question regarding cardiac rhythm or equipment availability was not included in the survey. These characteristic in combination with poor outcomes and limited use of DNACPR may suggest that attempted resuscitation remains a feature of end-of-life care in Sri Lanka. Sixty-four percent of patients who did not have ROSC received $>1$ vial of adrenaline during the resuscitation attempt, suggesting that these attempts were of a concerted nature lasting at least $2 \mathrm{~min}$.

Of the eight patients who had no CPR attempted before death, six patients were in wards where informal DNACPR instructions were in use. The use of informal DNACPR instructions, although often unwritten and infrequent, may be clinically effective in this setting. The cross-sectional nature of the survey precluded ascertaining the actual proportion of wards which utilize such instructions (as all doctors in a ward were not interviewed) and whether the patients who died without attempted resuscitation were the subject of these particular DNACPR instructions.

Junior doctors were "surprised" by the cardiac arrest in all the patients who went on to have ROSC but expressed "little" or "no surprise" at cardiac arrest in the vast majority of those who had unsuccessful resuscitation attempts [Figure 2]. Even allowing for bias due to the retrospective questioning and outcomes being known, opportunities for discussions regarding appropriateness of resuscitation or limitation of care may thus have been missed. Confounding influences on such decision-making in LMICs may include cultural norms, religious beliefs, public expectation, and lack of locally generated guidance. ${ }^{[3,7]}$ The impact, if any, of the family being present in nearly $75 \%$ of these attempts is not known and merits further exploration.

ROSC following resuscitation was low (12.8\%). This poor survival rate mirrors limited data from other LMICs such as Uganda $7.4 \%{ }^{[8]}$ and is lower than those reported from $\mathrm{HIC}$ ' $\mathrm{s}^{[1,4,9]}$ Although outcomes after resuscitation attempts for patients who have in-hospital cardiac arrests with nonshockable rhythms are poorer than when shockable, these findings highlight the need for urgent investment to improve resuscitation management in LMICs. ${ }^{[9]}$ Such efforts should be focused around early recognition and escalation of deteriorating patients where appropriate, combined with culturally appropriate efforts to research and implement the practice of appropriate DNACPR orders for patients where resuscitation is likely to be futile. In Europe, interdisciplinary resuscitation programs now include sessions considering the appropriate of resuscitation in an effort to reduce futile and undignified resuscitation attempts. ${ }^{[4,5,10]}$ Work is ongoing to provide similar training opportunities for nurses and doctors in Sri Lanka. ${ }^{[10]}$ Further research and investment in this area are justified.

This brief retrospective cross-sectional survey does not explore the underlying reasons for the cardiac arrests and subsequent resuscitations attempted. While suggesting a difference in perspectives of doctors between successful and unsuccessful attempts, it does not interrogate the appropriateness of resuscitation for each patient. Findings are difficult to generalize to all clinical staff on the ward.

\section{Conclusions}

CPR precedes the vast majority of in-patient ward deaths. Successful outcomes following resuscitation in Sri Lanka are lower than in HIC settings and similar to other LMICs. DNACPR orders (even informal) are not common in general wards. Most cardiac arrests were anticipated, nearly one-third of unsuccessful attempts do not appear to be concerted in nature and the likelihood of ROSC overall is low. LMICs such as Sri Lanka would benefit from better training and systems to care for the acutely deteriorating patient, further development of DNACPR orders, and from research and training in end-of-life decision-making. 


\section{Financial support and sponsorship}

Nil.

\section{Conflicts of interest}

There are no conflicts of interest.

\section{RefEREnCes}

1. Jones DA, Bagshaw SM, Barrett J, Bellomo R, Bhatia G, Bucknall TK, et al. The role of the medical emergency team in end-of-life care: A multicenter, prospective, observational study. Crit Care Med 2012;40:98-103.

2. Adhikari NK. Patient safety without borders: Measuring the global burden of adverse events. BMJ Qual Saf 2013;22:798-801.

3. Phua J, Joynt GM, Nishimura M, Deng Y, Myatra SN, Chan YH, et al. Withholding and withdrawal of life-sustaining treatments in Intensive Care Units in Asia. JAMA Intern Med 2015;175:363-71.

4. Bossaert LL, Perkins GD, Askitopoulou H, Raffay VI, Greif R, Haywood KL, et al. European resuscitation council guidelines for resuscitation 2015: Section 11. The ethics of resuscitation and end-of-life decisions. Resuscitation 2015;95:302-11.

5. British Medical Association. Decisions Relating to Cardiopulmonary
Resuscitation. A Joint Statement from the British Medical Association, the Resuscitation Council (UK) and the Royal College of Nursing. London: British Medical Association; 2007.

6. Clinical Trials.gov: A Service of the U.S. National Institutes of Health. National Cardiac Arrest Survey (NCAS). US: National Library of Medicine; 2016. Available from: https://www.clinicaltrials.gov/ct2/ show/NCT02368392?term $=$ cardiac + arrest\&rank=1. [Last accessed on 2016 Aug 20].

7. Friesen J, Patterson D, Munjal K. Cardiopulmonary resuscitation in resource-limited health systems-considerations for training and delivery. Prehosp Disaster Med 2015;30:97-101.

8. Ocen D, Kalungi S, Ejoku J, Luggya T, Wabule A, Tumukunde J, et al. Prevalence, outcomes and factors associated with adult in hospital cardiac arrests in a low-income country tertiary hospital: A prospective observational study. BMC Emerg Med 2015;15:23.

9. Findlay GP, Shotton H, Kelly K, Mason M. Time to Intervene? A Review of Patients Who Underwent Cardiopulmonary Resuscitation as a Result of an In-Hospital Cardiopulmonary Arrest. London: National Confidential Enquiry into Patient Outcome and Death; 2012.

10. Beane A, Stephens T, Silva AP, Welch J, Sigera C, De Alwis S, et al. A sustainable approach to training nurses in acute care skills in a resource limited setting (Network for intensive care skills training, NICST). Resuscitation 2016;101:e1-2. 